\section{Optic nerve changes in ocular toxoplasmosis}

\begin{abstract}
Purpose To determine the prevalence and features of the different types of involvement of the optic nerve in ocular toxoplasmosis. Methods Retrospective cross-sectional study. All patients with active ocular toxoplasmosis, consulting in the Uveitis Section of the Ophthalmology Department were selected. The involvement of the optic nerve was classified in the following categories: juxtapapillary retinochoroiditis, pure papillitis, neuroretinitis, distant lesion, and mixed lesion. Results The prevalence of involvement of the optic nerve found was $5.3 \%$. The optic nerve involvement with the presence of a concurrent active distant lesion, occurred in 22 eyes $(43.1 \%)$. A juxtapapillary lesion was found in 18 eyes (35.3\%). Eight eyes (15.7\%) presented lesions characterised as mixed. Isolated papillitis occurred in 3 eyes $(5.9 \%)$. Fortyseven lesions $(\mathbf{9 5 . 9 \% )}$ ) were unilateral and two (4.1\%) were bilateral. Twenty-eight eyes (54.9\%) had pre-existing lesions and $23(45 \%)$ were primary lesions. Visual acuity improved in 35 eyes $(71.4 \%)$ and remained unchanged in 14 eyes (28.5\%).

Conclusion The involvement of the optic nerve most frequently found in ocular toxoplasmosis was optic nerve oedema with a concurrent distant active lesion. The second type of lesion most often found was juxtapapillary retinochoroiditis. Involvement was monocular in most cases and the visual prognosis was favourable.
\end{abstract}

Eye (2007) 21, 746-751; doi:10.1038/sj.eye.6702319; published online 31 March 2006

Keywords: ocular toxoplasmosis; papillitis; neuroretinitis; juxtapapillary retinochoroiditis

\section{Introduction}

Uveitis is a worldwide prevalent disease, affecting people at productive age and it is a major cause of blindness. ${ }^{1}$ Ocular toxoplasmosis, in turn, is one of the most frequent aetiologies of posterior uveitis. ${ }^{2}$ In the State of Rio Grande do Sul, Brazil, it assumes considerable proportions, becoming a public health problem of extreme relevance. ${ }^{3}$

Ocular involvement in toxoplasmosis may result from acquired infection after birth or from the congenital form of the disease. ${ }^{4-8}$ The diagnosis is basically clinical, complemented by serologic tests in order to obtain evidence of previous exposure to the parasite. ${ }^{9}$

The involvement of the optic nerve in ocular toxoplasmosis was already described by several authors at the beginning of last century, and more recently new studies on this subject have appeared. Toxoplasma gondii may cause a lesion in the optic disc because of contiguousness; ${ }^{10,11}$ by direct involvement ${ }^{11-17}$ or even become involved when a retinochoroiditis lesion is located far from the optic nerve. ${ }^{8,9}$

The contiguous form was described by Jensen many years ago ${ }^{18}$ as a specific entity in four cases of juxtapapillary choroiditis, later considered as probably due to tuberculous aetiology. In 1952, Wilder recognised T. gondii histopathologically in necrotic retinochoroidal lesion in adult patients. ${ }^{19-21}$ Lesions had granulomatous character and marked necrosis in many instances led to a pathologic diagnosis of tuberculosis. So, currently it is accepted that most cases of Jensen's choroiditis are of toxoplasmic aetiology. This type of lesion consists of a typical area of retinochoroiditis in contact with a swollen optic disc and accompanied by a typical sectorial deficit in the visual field.

The direct involvement of the optic nerve by $T$. gondii was demonstrated histopathologically by the presence of different forms of the parasite inside it. ${ }^{22}$ At ophthalmoscopic observation, this involvement may be subdivided into pure anterior neuritis or papillitis and neuroretinitis. ${ }^{11}$ In pure papillitis the parasite affects the optic disc directly, causing a swollen 
papilla with sheathing of the peripapillary veins and there may be no concurrent active retinochoroiditis lesion. ${ }^{8}$ However, in the majority of these cases a peripheral scar lesion and vitreitis is always present over the optic disc. ${ }^{13,17}$

Neuroretinitis is characterised usually by a swollen optic nerve accompanied of papillo-macular or serous macular detachment of the retina associated to hard exudates in the macula distributed in a star shape. ${ }^{14,16,23,24}$

We have observed another form of involvement of the optic disc due to toxoplasmosis that would be caused secondarily by an active distant retinal lesion. ${ }^{9}$ In these cases there is an active focal necrotising retinochoroiditis lesion located at variable distances from the optic disc that presents changes that resembles papillitis. ${ }^{8}$ There are no detailed studies about this type of optic nerve involvement in the literature.

The objective of this study was to determine the total prevalence and the different types of involvement of the optic nerve in ocular toxoplasmosis, as well as to study several accompanying clinical parameters.

\section{Materials and methods}

The present retrospective cross-sectional study was performed in the Uveitis Section of the Ophthalmology Department at Hospital de Clínicas de Porto Alegre.

All patients attended in our Uveitis Section (926 records) who presented active ocular toxoplasmosis in the 1987-2001 period were reviewed. Patients who were immunocompromised and those who had a previous optic nerve lesion by causes other than toxoplasmosis were excluded. Patients with atrophic optic nerve caused by toxoplasmosis were also excluded because this alteration is considered a sequelae and in this study we wanted to evaluate the evolution of active lesions.

To be included in the study, the patient had to present alterations of the optic nerve in the form of swollen disc or papillitis concomitantly with the presence of an active ocular lesion caused by T. gondii.

The diagnosis of ocular toxoplasmosis was based on the presence of typical retinochoroiditis lesions and IgM- and/or IgG-specific antibodies for toxoplasmosis. The methods used for serology were indirect immunofluorescence reactions (IFI), ELFA (enzymelinked fluorescent assay) and MEIA (microparticle enzyme immunoassay) for IgM and IgG. Serological tests were also performed to detect other infectious diseases such as syphilis, rubella, herpes, cytomegalovirus, and tuberculosis. Fundoscopy was performed under mydriasis, with direct and indirect ophthalmoscope, and fundoscopic biomicroscopy with 78 diopter lens.
Angiography and retinography were also performed in all patients for documentation.

All patients were treated with the usual therapeutic scheme used in our Department. ${ }^{25}$ (Sulphadiazine $500 \mathrm{mg} 2 \mathrm{cp}$ four time/day, pyrimethamine $25 \mathrm{mg} 1 \mathrm{cp}$ two time/day, Folinic acid $7.5 \mathrm{mg}$ every day and oral corticosteropids - prednisone $1 \mathrm{mg} / \mathrm{kg}$ /day)

The files were analysed using a protocol containing the following data: patient identification, date of initial exam, eye affected, laterality, type of optic nerve lesion according to classification described elsewhere and initial and final visual acuity. The presence of pre-existing retinochoroiditis scars in the affected eye was also studied. The visual acuity was measured with Snellen chart at $6 \mathrm{~m}$ (better optical correction). The final visual acuity was measured when the lesion was considered cured (1-3 months).

The optic nerve involvement was classified as follows:

(1) Juxtapapillary retinochoroiditis: retinochoroidal lesion contiguous to the swollen optic disc (Figure 1).

(2) Pure Papillitis: swollen optic disc and sheathing of the peripapillary veins in the presence of a healed toxoplasmic retinochoroiditis lesion (Figure 2).

(3) Neuroretinitis: swollen optic disc, papillo-macular or serous macular detachment of the retina with hard exudates at the macula.

(4) Distant lesion: swollen optic disc in the presence of a distant active lesion (Figure 3).

(5) Mixed lesion: presence of more than one type of involvement previously described concurrently (Figure 4).

Statistical analysis of the data was performed by SPSS program version 10 . The $\chi^{2}$ Pearson statistical test and

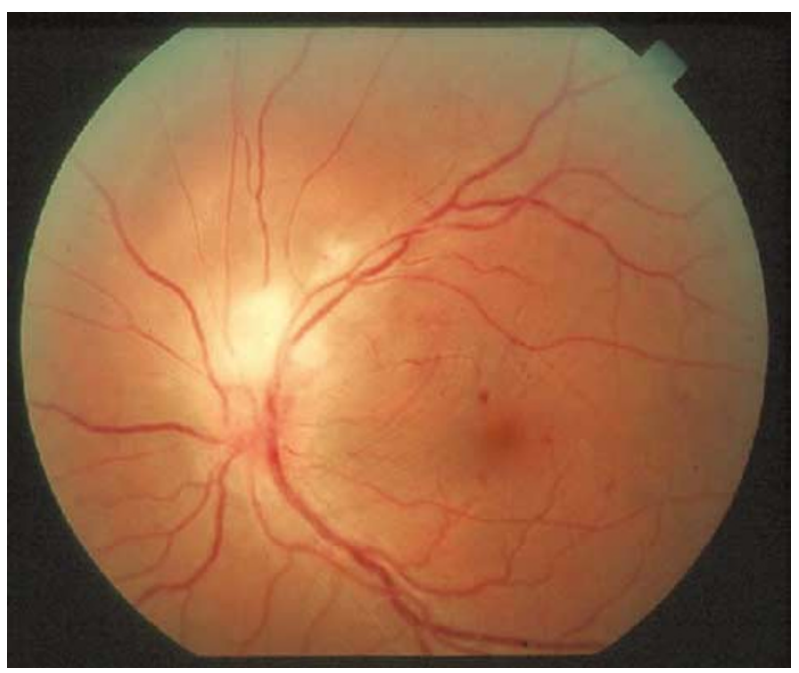

Figure 1 Retinography of a patient with superior juxtapapillary lesion and swollen disc. 


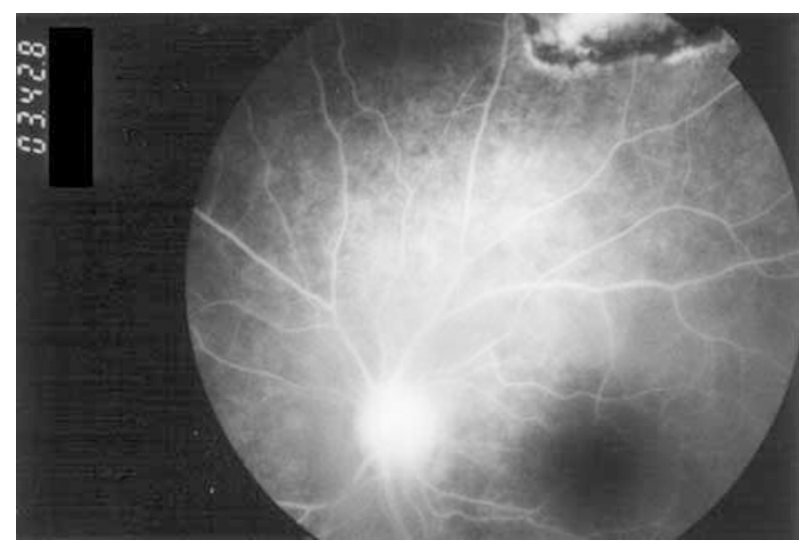

Figure 2 Fluorescent angiography showing swollen disc (hyperfluorescence) with a superior retinochoroiditis scar.

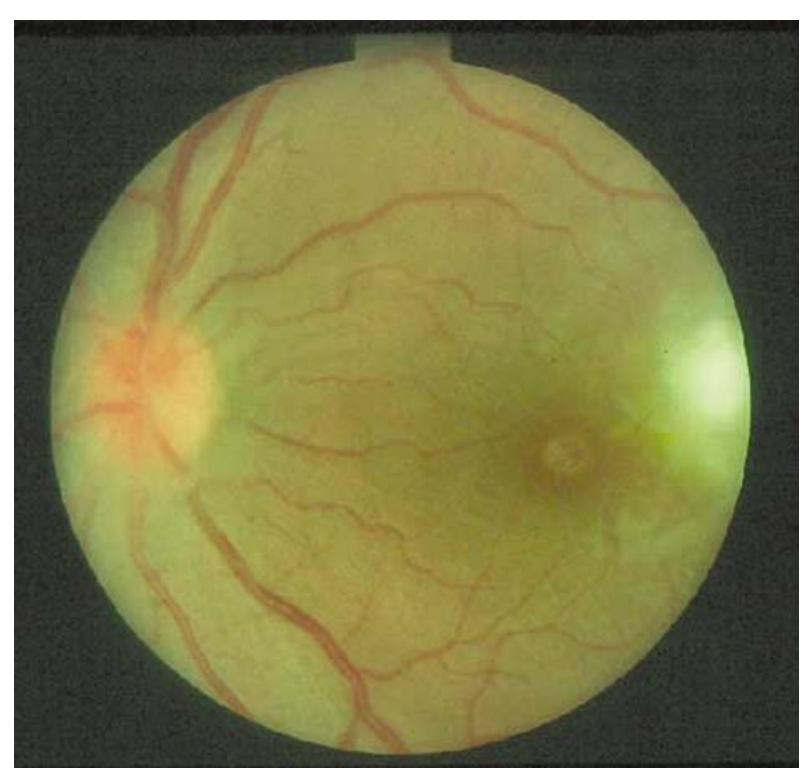

Figure 3 Photograph showing temporal white lesion with concomitant swollen disc.

$t$-Student's test were also applied. The level of significance considered was 0.05 .

The present study was approved by the Ethics Comitee of the Hospital de Clínicas de Porto Alegre.

\section{Results}

Of the 926 patients, 49 patients (51 eyes) had involvement of the optic nerve with a total prevalence of $5.03 \%$. The mean age of the patients with changes in the optic disc was 27 years and 4 months (with a variation of 6-65 years) (Table 1). The optic nerve involvement concomitantly with a distant lesion occurred in 22 eyes

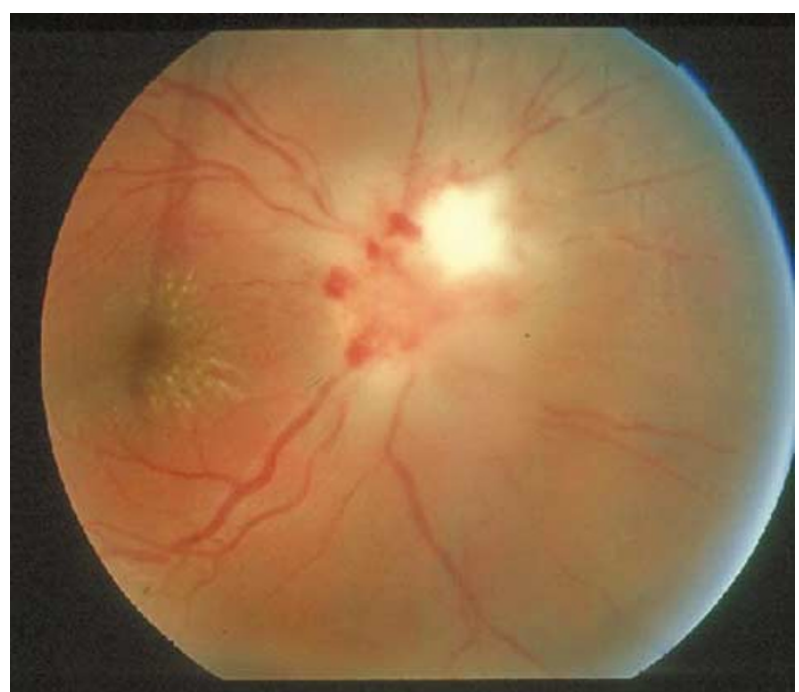

Figure 4 Mixed lesion with a retinal white exsudate superior to swollen optic disc and a macular star (a juxtapapillary lesion mixed with a neurorretinitis).

(43.1\%). The involvement of the optic disc by a juxtapapillary lesion occurred in 18 eyes (35.3\%). Eight eyes $(15.7 \%)$ presented more than one type of lesion concurrently, being characterised as mixed. Of these eight eyes, six eyes $(75 \%)$ presented a distant lesion associated with neuroretinitis and two $(25 \%)$ presented with juxtapapillary lesion and neurorretinitis. The pure papillitis occurred in three eyes (5.9\%) (Graph 1). No cases of isolated neuroretinitis were found.

Forty-seven had (95.9\%) unilateral lesions and two (4.1\%) had bilateral (Table 1).

Twenty-eight eyes (54.9\%) had pre-existing lesions and $23(45 \%)$ were primary lesions (Table 1$)$.

After treatment the visual acuity improved in 35 eyes $(71.4 \%)$, and remained unchanged in 14 eyes $(28.5 \%)$ (Graph 2). Patients with mixed lesions had the best visual prognosis because $75 \%$ of them improved visual acuity. The percentage of improval visual acuity was 66.6, 63.63, and $61.1 \%$ in papillitis, distant lesions, and juxtapapillary lesions, respectively.

\section{Discussion}

Ocular toxoplasmosis is very frequent in Rio Grande do Sul, and it is the main cause of uveitis in our

Department. ${ }^{3}$ After many years of observations, we could verify a wide variety of clinical presentations of this disease. ${ }^{26}$ Concomitantly, we have had opportunity to observe and treat a considerable number of patients presenting with optic nerve alterations. Although the prevalence found in our study seems not to be very high (5.3\%) this type of involvement represents concern for 
Table 1 Involvement of optic nerve in patients with ocular toxoplasmosis

\begin{tabular}{|c|c|c|c|c|c|c|c|}
\hline & Type of lesion & Eye & Age & Laterality & Pre-existing lesions & Initial VA & Final VA \\
\hline 1 & Mixed & RE & 38 & $\mathrm{U}$ & - & $\mathrm{HM}$ & 0.5 \\
\hline 2 & Juxtapapillary & LE & 34 & $\mathrm{U}$ & + & $\mathrm{CF}$ & 0.8 \\
\hline 3 & Juxtapapillary & $\mathrm{RE}$ & 34 & $\mathrm{U}$ & + & 0.8 & 1 \\
\hline 4 & Distant & LE & 61 & $\mathrm{U}$ & - & 0.5 & 0.5 \\
\hline 5 & Distant & LE & 27 & $\mathrm{U}$ & + & $\mathrm{CF}$ & $\mathrm{CF}$ \\
\hline 6 & Mixed & LE & 20 & $\mathrm{U}$ & - & 0.1 & 1 \\
\hline 7 & Juxtapapillary & RE & 26 & $\mathrm{U}$ & + & 0.1 & 1 \\
\hline 8 & Distant & RE & 21 & $\mathrm{U}$ & - & CF & CF \\
\hline 9 & Juxtapapillary & RE & 24 & $\mathrm{U}$ & - & 0.33 & 1 \\
\hline 10 & Distant & LE & 26 & $\mathrm{U}$ & + & 0.33 & 0.5 \\
\hline 11 & Mixed & LE & 43 & $\mathrm{U}$ & + & 0.1 & 1 \\
\hline 12 & Juxtapapillary & RE & 65 & $\mathrm{U}$ & - & 0.5 & 1 \\
\hline 13 & Distant & RE & 19 & $\mathrm{U}$ & + & $\mathrm{CF}$ & $\mathrm{CF}$ \\
\hline 14 & Distant & LE & 16 & $\mathrm{U}$ & - & 0.4 & 0.5 \\
\hline 15 & Mixed & LE & 27 & $\mathrm{U}$ & - & 0.1 & 0.33 \\
\hline 16 & Distant & RE & 26 & $\mathrm{U}$ & + & 0.1 & 0.5 \\
\hline 17 & Distant & LE & 17 & $\mathrm{U}$ & + & HM & 0.1 \\
\hline 18 & Distant & LE & 41 & $\mathrm{U}$ & + & 0.2 & 0.2 \\
\hline 19 & Distant & RE & 36 & $\mathrm{U}$ & + & 0.2 & 1 \\
\hline 20 & Juxtapapillary & LE & 32 & $\mathrm{U}$ & + & 0.33 & 0.6 \\
\hline 21 & Juxtapapillary & LE & 38 & $\mathrm{U}$ & + & 0.1 & 0.6 \\
\hline 22 & Juxtapapillary & LE & 29 & $\mathrm{U}$ & - & 1 & 1 \\
\hline 23 & Mixed & RE & 13 & $\mathrm{U}$ & - & $\mathrm{CF}$ & 1 \\
\hline 24 & Mixed & RE & 14 & $\mathrm{U}$ & - & 0.7 & 1 \\
\hline 25 & Juxtapapillary & LE & 34 & $\mathrm{U}$ & - & 1 & 1 \\
\hline \multirow[t]{2}{*}{26} & Papillitis & RE & 17 & B & + & 1 & 1 \\
\hline & Papillitis & LE & & & - & 0.1 & 0.2 \\
\hline 27 & Distant & LE & 29 & $\mathrm{U}$ & + & 0.7 & 1 \\
\hline 28 & Distant & RE & 26 & $\mathrm{U}$ & + & 0.2 & 1 \\
\hline 29 & Distant & LE & 25 & $\mathrm{U}$ & - & 0.1 & 0.5 \\
\hline 30 & Distant & RE & 11 & $\mathrm{U}$ & + & 0.2 & 0.5 \\
\hline 31 & Juxtapapillary & $\mathrm{RE}$ & 44 & $\mathrm{U}$ & + & 0.1 & 1 \\
\hline 32 & Distant & LE & 13 & $\mathrm{U}$ & + & 0.1 & 0.6 \\
\hline 33 & Distant & LE & 30 & $\mathrm{U}$ & - & 0.1 & 0.3 \\
\hline 34 & Distant & LE & 20 & $\mathrm{U}$ & - & 0.2 & 1 \\
\hline 35 & Juxtapapillary & RE & 39 & $\mathrm{U}$ & + & 0.6 & 1 \\
\hline \multirow[t]{2}{*}{$36^{\mathrm{a}}$} & Distant & $\mathrm{RE}$ & 6 & $\mathrm{~B}$ & + & - & 0.3 \\
\hline & Distant & LE & & & + & - & 0.1 \\
\hline 37 & Juxtapapillary & RE & 20 & $\mathrm{U}$ & + & $\mathrm{CF}$ & 0.1 \\
\hline 38 & Distant & LE & 24 & $\mathrm{U}$ & - & 0.8 & 1 \\
\hline 39 & Juxtapapillary & RE & 22 & $\mathrm{U}$ & + & 0.1 & 0.1 \\
\hline 40 & Mixed & LE & 15 & $\mathrm{U}$ & - & $\mathrm{CF}$ & 0.2 \\
\hline 41 & Juxtapapillary & LE & 32 & $\mathrm{U}$ & + & 0.2 & 0.2 \\
\hline 42 & Juxtapapillary & RE & 11 & $\mathrm{U}$ & + & 0.1 & 0.1 \\
\hline 43 & Papillitis & RE & 25 & $\mathrm{U}$ & - & $\mathrm{HM}$ & 0.2 \\
\hline 44 & Juxtapapillary & LE & 36 & $\mathrm{U}$ & + & 0.5 & 0.9 \\
\hline 45 & Juxtapapillary & LE & 64 & $\mathrm{U}$ & - & 1 & 1 \\
\hline 46 & Mixed & LE & 14 & $\mathrm{U}$ & - & 1 & 1 \\
\hline 47 & Juxtapapillary & $\mathrm{RE}$ & 21 & $\mathrm{U}$ & - & 0.8 & 0.8 \\
\hline 48 & Distant & LE & 18 & $\mathrm{U}$ & - & 0.33 & 1 \\
\hline 49 & Distant & LE & 7 & $\mathrm{U}$ & + & 0.4 & 0.6 \\
\hline
\end{tabular}

$\mathrm{RE}=$ right eye; $\mathrm{LE}=$ left eye; $\mathrm{U}=$ unilateral; $\mathrm{B}=$ bilateral; $\mathrm{CF}=$ count fingers; $\mathrm{HM}=$ hand's movements; $-=$ primary lesion; $+=$ Pre-existing lesion; $\mathrm{VA}=$ visual acuity.

apatient with congenital toxoplasmosis, examined for the first time at the age of 3 months.

the clinician because of severity of the disease and the diagnostic difficulties with other types of neuritis.

The optic nerve involvement in the presence of an active distant retinochoroiditis was the most frequent type of lesion found in our study. Some authors ${ }^{27,28}$ do not consider optic disc swelling caused by distant lesion as true papillitis but as a reactive oedema of the optic nerve due to a hypersensitivity reaction, and then the 


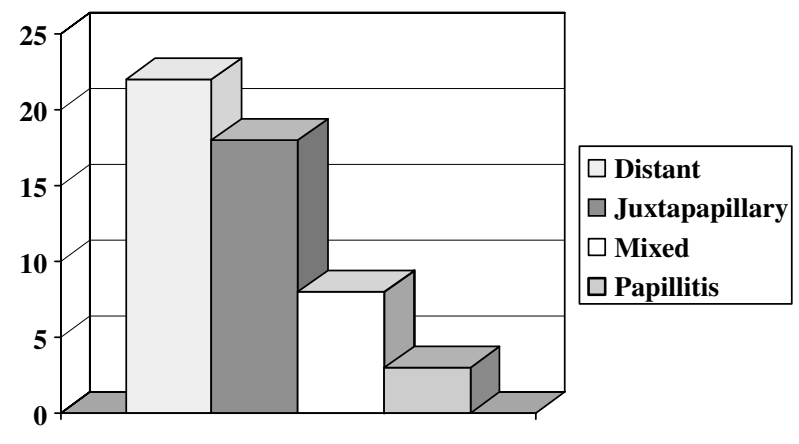

Graph 1 Types of involvement of optic nerve.

alteration is then called secondary papillitis. ${ }^{27}$ This study shows that they evolve favourably with treatment and usually do not leave any permanent change in the optic nerve $(63.63 \%$ of patient had improve visual acuity after resolution of inflammation).

The second most numerous group was represented by a swollen optic disc with a juxtapapillary lesion. Although the clinical appearance is usually very serious, with a large amount of exudates, hemorrhage, optic nerve oedema and low visual acuity, this type of change responds rapidly to medication, reabsorbing the oedema and leaving a typical retinal pigmented lesion. A scar may not be apparent at the beginning of the disease and became evident later. ${ }^{17}$ In some cases, a glial reaction remains on the optic disc.

Eight eyes presented mixed lesions and all these cases neuroretinitis was present. In 1977, Gass ${ }^{29}$ postulated the pathophysiological mechanisms of this entity. It is possible that papillitis and the macular star found, together with a distant toxoplasmic retinochoroiditis, occurs as a hypersensitivity reaction and not due to direct damage caused by the parasite to the optic nerve as described in isolated neuroretinitis. ${ }^{29}$

Toxoplasmosis is an infrequent cause of pure papillitis. In our study, three eyes presented this manifestation $(5.9 \%)$. The findings that suggest the direct injury of the optic nerve by the parasite are the presence of optic nerve inflammation, vitreitis, a healed toxoplasmic lesion, and the presence of toxoplasmic antibodies. Other causes of swollen optic disc, such as demyelination diseases, vasculitis of the optic disc, ischaemic optic neuropathy, increased intracranial pressure, sarcoidosis, systemic lupus erythematosus, toxocariasis, optic nerve tumor, and other infectious causes of retinitis must always be excluded. ${ }^{13}$

In the present study, 28 eyes already had a toxoplasmic lesion before the optic nerve become involved, suggesting recurrences of an old disease and in 23 eyes the lesion of the optic nerve was the first ocular manifestation of ocular infection by the parasite.

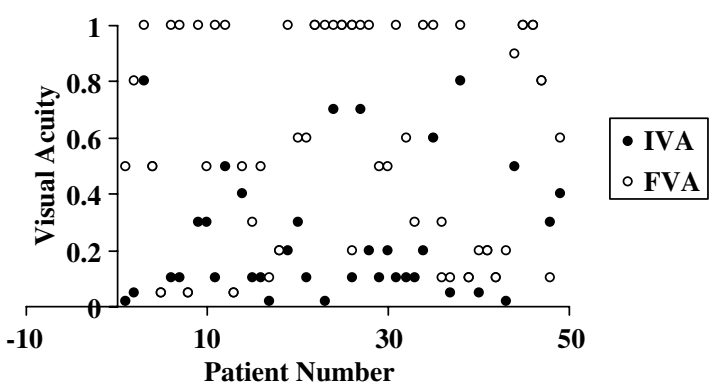

Graph 2 Initial and final visual acuity of the whole sample (IVA, initial visual acuity; FVA, final visual acuity).

There was a marked dominance of unilateral lesions in our sample. Only two patients presented a change in the optic nerve in both eyes. One of these patients had proven congenital toxoplasmosis and the other had probable of congenital infection, but we did not confirm the diagnosis.

Some patients of this study performed visual field testing, that was recorded using the Humphrey 24/2 FastPac Strategy but we did not evaluate this records because few patients was submitted to this examination. Stanford $e a^{30}$ suggest in their study that toxoplasmic retinochoroidal scars close to the optic disc are associated with absolute defects. In the other hand, lesions that are far from the disc are more likely to produce relative defects.

The involvement of the optic nerve in ocular toxoplasmosis may lead an inexperienced clinician to think that visual acuity may be severely and permanently affected. However, in most of the cases we initially observe a low visual acuity that after treatment and with the healing of the lesion, improves significantly.

Concerning this point our findings are coincident with those in the literature. ${ }^{13,14,16,17,24,31}$ The final visual acuity depends basically on the location of the retinal lesion, and not on the involvement of the optic disc.

\section{References}

1 Michel SS, Foster CS. Definition, classification, etiology and epidemiology. In: Foster CS, Vitale AT (eds). Diagnosis and Treatment of Uveitis. WB. Saunders Company: Philadelphia, 2002, pp 17-26.

2 Oréfice F, Bonfioli AA. Toxoplasmose. In: Oréfice F (ed). Uveite: Clinica \& Cirurgia: Atlas \& Texto. Cultura Médica: Rio de Janeiro, 2000, pp 619-680.

3 Melamed J, Güntzel I, Lindenmeyer R. Uveitis in Southern Brazil. Uveitis in Third Millennium. Elsevier Science: Amsterdam, 2000, pp 247-250.

4 Perkins ES. Ocular Toxoplasmosis. Brit J Ophthal 1973; 57: 1-17.

5 Melamed J. Peculiaridades da toxoplasmose ocular no Rio Grande do Sul. Arq Bras Oftal 1988; 51(5): 197-200. 
6 Silveira C, Belfort Jr R, Burnier Jr M, Nussenblatt R. Acquired toxoplasmic infection as the cause of toxoplasmic retinochoroiditis in families. Am J Ophtalmol 1988; 106: 362-364.

7 Nussenblatt RB, Belfort Jr R. Ocular toxoplasmosis - an old disease revisited. JAMA 1994; 271: 304-307.

8 Gonçalves EC, Oréfice F, Mendes AG, Pedroso EP. Toxoplasmose ocular adquirida tardia. Relato de três casos simultâneos da mesma família. Revista Brasileira de Oftalmologia 1995; 54(5): 57-60.

9 Melamed J. Toxoplasmose ocular. In: Lavinsky J (ed). Doenças Prevalentes da Retina e Vitreo. Cultura Médica: Rio de Janeiro, 2002, pp 597-620.

10 Uchida Y, Kakehashi Y, Kameyama K. Juxtapapillary retinochoroiditis with psychiatric disorder possibly caused by toxoplasma. Am J Ophhalmol 1978; 86: 791-793.

11 Banta JT, Davis JL, Lam BL. Presumed toxoplasmic anterior optic neuropathy. Ocul Immunol Inflamm 2002; 10(3): 201-211.

12 Berengo A, Frezzoti R. Active neuro-ophtalmic toxoplasmosis. A clinical study on 19 patients. Adv Ophthalmol 1962; 12: 265.

13 Folk JC, Lobes L. Presumed toxoplasmic papillitis. Ophthalmol 1984; 91: 64-67.

14 Moreno RJ, Weisman J, Waller S. Neuroretinitis: an unusual presentation of ocular toxoplasmosis. Ann Ophthalmol 1992; 24: 68-70.

15 Williams N, Miller NR. Neuroretinitis. In: Pepose JS, Holland GN, Wilhelmus KR (eds). Ocular Infection $\mathcal{E}$ Immunity, 1st ed. Mosby: St Louis, 1996, pp 601-608.

16 Fish RH, Hoskins JC, Kline CLB. Toxoplasmosis neuroretinitis. Ophthalmol 1993; 100: 1177-1182.

17 Song A, Scott IU, Davis JL, Lam BL. Atypical anterior optic neuropathy caused by toxoplasmosis. Am J Ophthalmol 2002; 133: $162-164$.

18 Jensen E. Retino-choroiditis juxtapapillaris. Arch F Ophthal 1908; 69: 41
19 Wilder HC. Toxoplasma chorioretinitis in adults; a preliminary study of forty-one cases diagnosed by microscopic examination. Arch Ophthalmol 1952; 47(4): 425.

20 Wilder HC. Toxoplasma chorioretinitis in adults. Arch Ophthalmol 1952; 48(4): 127-136.

21 Holland GN, Lewis KG, O'Connor GR. Ocular toxoplasmosis: a 50th anniversary tribute to the contribuitions of Heleonor Campbell Wilder Foester. Arch Ophthalmol 2002; 120(8): 1081-1084.

22 Manshot WA, Daamen CBF. Connatal ocular toxoplasmosis. Arch Ophtalmol 1965; 74: 48.

23 Maitland CG, Miller NR. Neuroretinitis. Arch Ophthalmol 1984; 102: 1146-1150.

24 Küçükerdönmez C, Akova Y, Yilmaz G. Ocular toxoplasmosis presenting as neuroretinitis: report of two cases. Ocul Immunol Inflamm 2002; 10(3): 229-233.

25 Melamed J. Tratamento da toxoplasmose ocular. Rev Bras Oftal 1998; 57(2): 159-163.

26 Melamed J, Eckert GU, Cagliari PZ. Atypical lesions in ocular toxoplasmosis. Uveitis in Third Milleniun. Elsevier Science: Buenos Aires, 2000, pp 265-268.

27 Schlaegel Jr TF. Toxoplasmosis. In: Duane TD (ed). Clin Ophthalmol. Hagerstown: Harper \& Row, 1982, Vol. 4, Chap 51.

28 Bosch-Driessen LE, Berendschot TT, Ongkosuwito JV, Rothova A. Ocular toxoplasmosis: clinical features and prognosis of 154 patients. Ophthalomology 2003; 109: 869-878.

29 Gass JDM. Optic nerve diseases that may masquerade as macular disease. In: Gass JDM (ed). Stereoscopic Atlas of Macular Diseases Diagnosis and Treatment. Mosby: USA, 1997, pp 996-999.

30 Stanford MR, Tomlin EA, Comyn O, Holland K, Pavesio C. The visual field in toxoplasmic retinochoroiditis. Brit Journ Ophthalmol 2005; 89: 812-814.

31 Smith JR, Cunninggham ET. Atypical presentations of ocular toxoplasmosis. Curr Opin Ophthalmol 2002; 13(6): 387-392. 